\title{
Foliar Biophenolic Antioxidant Metabolites of Alternanthera bettzickiana
}

\author{
A.J.A. PETRUS ${ }^{1 *}$, K. KALPANA and A. BHARADHA DEVI \\ 'Department of Chemistry, Tagore Arts College, Puducherry - 605008, India. \\ Department of Chemistry, Kanchi Mamunivar Centre for Post-Graduate Studies \\ (Autonomous), Puducherry - 605008, India. \\ *Corresponding author E-mail: ajapetrus@ hotmail.com \\ http://dx.doi.org/10.13005/ojc/300334
}

(Received: July 29, 2014; Accepted: September 01, 2014)

\begin{abstract}
Alternanthera bettzickiana (Regel) Nicholson (Family: Amaranthaceae) is an erect herb and an ornamental pot plant, claimed to be useful in purifying and nourishing blood, in addition to the acclaimed soft laxative, galactagogue, antipyretic and wound healing characteristics. The tender leaves and shoots are commonly consumed like vegetable or spinach and in soups, either cooked alone or mixed with other vegetables and served with a staple food like rice or ugali. From the hydrophilic extract of the fresh leaves that exhibited in vitro antioxidant/radical scavenging (ABTS ${ }^{*}$ and FRAP assays) and metal (Ferrous ion) chelating capacities, six biophenolic antioxidants, viz., 7-O- $\beta$-D-glucopyranosyl-6- $C$ - $\beta$-D-glucopyranosylapigenin, 6 - $C$ - $\beta$-D-glucopyranosylapigenin, 8- $C$ - $\beta$ D-glucopyranosylapigenin, (E)-3-(4-hydroxyphenyl)prop-2-enoic acid, (E)-3-(3,4-dihydroxyphenyl) prop-2-enoic acid and (E)-3-(4-hydroxy-3-methoxyphenyl)prop-2-enoic acid, have been isolated and characterised for the first time adopting extensive chromatographic and spectral studies.
\end{abstract}

Key words: Alternanthera bettzickiana, Amaranthaceae, Antioxidant capacity, Metal ion chelating capacity, Glycoflavone, Hydroxycinnamate.

\section{INTRODUCTION}

Alternanthera bettzickiana (Regel) Nicholson ${ }^{1,2}$ (Family: Amaranthaceae), commonly known in English as Baptist plant, border plant, calico plant, red calico plant, Jacob's coat, Joseph's coat and parrot leaf, is an erect and bushy or prostrate perennial herb with food and ornamental values. The leaves are green or reddish and sometimes both. The tender leaves and shoots are commonly consumed like vegetable or spinach and in soups, either cooked alone or mixed with other vegetables such as cowpeas or amaranth, with added coconut milk and served with a staple food like rice or ugali ${ }^{1}$. The whole plant is reported to be useful in purifying and nourishing blood and is claimed to be a soft laxative, 
a galactagogue and an antipyretic, in addition to its wound healing property ${ }^{2}$. The acetone extract has been found to possess lipoxygenase, tyrosinase and xanthine oxidase inhibitory activities ${ }^{3}$ and the aqueous ethanolic extract of the whole plant has recently been reported to exhibit antioxidant benefit and improve hepatic oxidant-antioxidant balance in the ovariectomized mice ${ }^{4}$. Earlier studies have reported the characterisation of simple and acylated betacyanins from the leaves ${ }^{5}$.

Increased consumption of fruits and vegetables has consistently been observed to reduce the risk of chronic diseases including cardioand cerebro-vascular diseases, certain forms of cancer, hypertension, type 2 diabetes mellitus and stroke, worldwide. Concomitantly, chronic diseases are also the leading cause of mortality worldwide. Food plants that manifest potential health benefits biosynthesise a wide array of bioactive constituents and the protection is due, largely, to the plethora of bioactive metabolites, both nutritive and non-nutritive, biosynthesised by plants. Evidences accumulating to date from both laboratory and clinical studies tend to support that oxidative stress, imposed by reactive oxygen, nitrogen and chlorine species, plays a pivotal role in the aging process and in the pathophysiology of age-related diseases, particularly atherosclerosis, neurodegenerative disorders, immune functions and all stages of carcinogenesis. Consequently, the control of 'redox' status with the properties of food and food components has emerged as a salient field of research today. Dietary interventions are, therefore, among the emerging trends to curtail physiological malfunctioning including cancer, diabetes mellitus, cardiac complications, hypertension and neurodegenerative disorders, in addition to stimulating the immune system, improving drug metabolism and tissue regeneration ${ }^{6}$. Antioxidation is frequently cited to be the key property underlying the prevention and/or reduction of these chronic and age-related disorders as well as skin deterioration by dietary plant biophenolics and other plant phenolcontaining commodities 6 . Hence, characterisation of the antioxidant capacities of these food plants as well as the dietary antioxidants present in them provide a better insight into their functionality, as these dietary constituents are necessary to cope up with the initiation or propagation of the reactive oxidants. In continuation of our investigations on the
South Indian species of Alternanthera ${ }^{2,7}$, the reactive species scavenging and pro-oxidant metal chelating capacities as well as the antioxidant constitution of the fresh leaves of $A$. bettzickiana, collected from wild habitat, are reported in this paper.

\section{MATERIALS AND METHODS}

\section{Preparation of plant extract}

Fresh leaves of $A$. bettzickiana ( $800 \mathrm{~g}$ ) were collected from the wild population of the Vadalur area of Cuddalore District, Tamil Nadu, in the month of February. After establishing the identity of the taxon, the material was extracted exhaustively using $80 \%$ aqueous methanol ( $4 \times 8 \mathrm{~L}$, ambient, $48 \mathrm{~h}$ ) and concentrated under reduced pressure to get the crude extract-concentrate.

\section{Chemicals, Reagents and Instruments}

2,2'-Azinobis(3-ethylbenzothiazoline-6sulphonic acid) (ABTS) diammonium salt, 2,4,6-tris(2pyridyl)-s-triazine (TPTZ), 3-(2-pyridyl)-5,6-di(4phenylsulphonic acid)-1,2,4-triazine (ferrozine) sodium salt, ethanol, ferrous chloride and rutin were obtained from Sigma-Aldrich Inc. and Sephadex LH-20 from Pharmacia. Microcrystalline cellulose for thin layer chromatography and methanol for spectroscopy were procured from Merck Specialities Private Limited. All other chemicals/reagents were of analytical/laboratory grades from Himedia/Merck. Shimadzu UV-160 Spectrophotometer was used for electronic spectral measurements and NMR spectral recordings were performed in Bruker DRX-500 spectrometer, using DMSO- $d_{6}$ solutions.

\section{Determination of total phenolic content}

The total phenolic content of the crude extract was determined by the spectrophotometric method adopting the protocol described earlier ${ }^{8}$ and expressed as $\mathrm{mg}$ gallic acid equivalent (GAE)/100 $\mathrm{g}$ fresh leaves. The determination was repeated three times and the mean $\pm S D$ of the three measurements was taken as before.

\section{Fractionation of the hydrophilic extract}

The extract-concentrate was then partitioned into crude lipophilic and hydrophilic fractions, by successively washing with $(\mathrm{Me})_{2} \mathrm{CO}$ $(3 \times 5 \mathrm{~L}$, ambient, $48 \mathrm{~h})$ and $\mathrm{MeOH}(4 \times 6 \mathrm{~L}$, ambient, $48 \mathrm{~h}$ ) and the two fractions were concentrated under 
reduced pressure to get the respective concentrates. The more polar hydrophilic concentrate of the extract was then subjected to gel chromatography [sephadex LH 20, eluting with aq. $\mathrm{MeOH}(95 \%)]$ resulting in the collection of 12 fractions, numbered serially from 1-12. Based on their conventional paper chromatographic (PC) characteristics ${ }^{9}$, the eluates were grouped into four fractions: $F_{1}(1$ and 2), $F_{2}(3-5), F_{3}(6-9)$ and $F_{4}(10-12)$. All the four fractions were evaluated for their in vitro antioxidant, reactive species scavenging and metal ion chelating capacities (Table 1).

\section{Determination of Vitamin C equivalent antioxidant capacity}

ABTS radical cation (ABTS*) scavenging capacity and ferric-reducing/antioxidant power (FRAP) of the hydrophilic extract were determined by the procedures described previously 8,10 and expressed as vitamin $C$ equivalent antioxidant capacity (VCEAC). The VCEAC of the extractfractions (200 mg/L) and standard rutin (10 mg/L) were expressed as percentage, as detailed before. All data were recorded as mean $\pm S D$, computed from three replications.

\section{Determination of transition metal ion chelating capacity}

Pro-oxidant metal chelating capacities of the hydrophilic extract-fractions $(200 \mathrm{mg} / \mathrm{L})$ and standard rutin $(10 \mathrm{mg} / \mathrm{L})$ were evaluated using $\mathrm{Fe}^{\prime \prime}$ and the percentage inhibition of the ferrozine-Fe" complex formation was calculated adopting the methodology described earlier ${ }^{8,10}$, in triplicate. The ubiquitous flavonoid rutin was used as positive standard as before.

\section{Isolation and characterisation of the biophenols}

Activity-guided fractionation of $F_{1}-F_{4}$ has resulted in the rejection of $F_{1}$ and the rechromatography of the combined $\mathrm{F}_{2}$ and $\mathrm{F}_{3}$, using the same column [sephadex $\mathrm{LH} 20$, aq. $\mathrm{MeOH}$ $(95 \%), 28 \pm 2^{\circ} \mathrm{C}$ ] to resolve five further fractions, $R_{1}-R_{5}$. Fractions $R_{2}$ and $R_{3}$ that appeared homogeneous in $\mathrm{PC}$ characteristics were combined together and left in the ice chest to yield a homogenous compound 1 . The isolate was recrystallised using $\mathrm{MeOH}$ and the pure metabolite was characterised as 7-O- $\beta$-D-glucopyranosyl-6- $C$ -
$\beta$-D-glucopyranosylapigenin ${ }^{10}$ (Fig 1). The combined $R_{4}$ and $R_{5}$ fractions was subjected to preparatory thin layer chromatographic separation [microcrystalline cellulose, $20 \times 20 \mathrm{~cm}, 0.5 \mathrm{~mm}$, aq. HOAc (15\%), $28 \pm 2^{\circ} \mathrm{C}$ ] to isolate two homogeneous solids, labeled compound $2\left(R_{f} 0.50\right)$, characterised as $6-C-\beta-D$ glucopyranosylapigenin ${ }^{7}$ and compound $3\left(R_{f} 0.31\right)$, characterised as 8-C- $\beta$-D-glucopyranosylapigenin ${ }^{7}$ (Fig 1). The mother liquors of the combined $\mathrm{F}_{2}+\mathrm{F}_{3}$ and combined $R_{4}+R_{5}$, together with $F_{4}$ fractions were pooled together and rechromatographed [Sephadex $\mathrm{LH}-20$, aq. $\mathrm{MeOH}(90 \%), 28 \pm 2^{\circ} \mathrm{C}$ ] and then subjected to PC [Whatman No.3, $\mathrm{H}_{2} \mathrm{O}$, descending, $\left.28 \pm 2^{\circ} \mathrm{C}\right]$ to separate compound $5\left(R_{t}\right.$ 0.83 ), characterised as (E)-3-(4-hydroxyphenyl)prop2-enoic acid ${ }^{11}$, compound $6\left(R_{f} 0.66\right)$, characterised as (E)-3-(3,4-dihydroxyphenyl)prop-2-enoic acid ${ }^{11}$ and compound $7\left(R_{f} 0.75\right)$, characterised as $(E)-3-$ (4-hydroxy-3-methoxyphenyl)prop-2-enoic acid ${ }^{12}$.

\section{RESULTS AND DISCUSSIONS}

Fruits, vegetables and leafy-greens have generated interest worldwide, in the recent past, as they have been consistently found to exhibit multiple benefits for human health. It is known fairly well that globally the indigenous ethnic communities utilise locally available plant resources as part of their diet for the health care needs and derive protection against various ailments. The protection has often been attributed to the variety of antioxidant phytometabolites produced and stored in them. These dietary antioxidants contribute considerably to the defense against oxidative stress and the consequent risk of chronic diseases ${ }^{6}$. Characterisation of the dietary antioxidants and their capacities have therefore become essential to ascertain their pharmacological evaluation, to validate the safety and traditional uses of such indigenous plant food and also to standardise various preparations of these plants. The tender leaves and shoots of $A$. bettzickiana, locally called seemai ponankanni keerai and by the Paniya, Kattunaikka, Kuruma and other tribes of Wayanad district of Kerala as Cherucheera, ${ }^{13,14}$ are commonly used like vegetable in several parts of Asia. The Chinese call it Jin xiu xian, while the Japanese address it as akaba-moyô-biyu, whereas in Tanzania, the herb is referred to as mchicha, mchicha maua. 
Determination and characterisation of the phenolics

The total amount of phenolics present in $100 \mathrm{~g}$ of $A$. bettzickiana leaves is found to be 308.526 $\mathrm{mg} \mathrm{GAE}$, which is greater than the amount that has been determined from the indigenous leafy vegetable, Mukia maderaspatana $^{8}(292.392 \mathrm{mg})$ and that recorded for Leucas aspera' ${ }^{15}(231.000 \mathrm{mg})$. However, it is less than that reported for Cleome gynandra ${ }^{16}(321.000 \mathrm{mg})$. The major biophenol contributing to the total phenolics has been characterised as 7-O- $\beta$-D-glucopyranosyl-6-C- $\beta$-Dglucopyranosylapigenin (1), by direct comparison of the chromatographic and spectral characteristics with the compound isolated from M. maderaspatana ${ }^{10}$. The other biophenols belonging to the flavone sub-class ${ }^{6}$ that have been characterised are $6-C$ - $\beta$-D-glucopyranosylapigenin (2) and 8-C- $\beta$-D-glucopyranosylapigenin (3) that have been reported to occur in $A$. pungens ${ }^{7}$. The major bioflavonoids of this leafy vegetable are thus made of the basic 5,7,4'-trihydroxyflavone (apigenin) skeleton (4) (Fig. 1). Three monocyclic phenolic acids ${ }^{6}$, belonging to the sub-class of hydroxycinnamates viz., (E)-3-(4-hydroxyphenyl)prop-2-enoic acid ${ }^{11}$ (5), (E)-3-(3,4-dihydroxyphenyl)prop-2-enoic acid ${ }^{11}$ (6), and (E)-3-(4-hydroxy-3-methoxyphenyl)prop2-enoic acid $^{12}(7)$, have also been characterised, in addition to the three glycoflavones (Fig. 1). To the best of our knowledge, the biophenolic composition of the functional leafy vegetable is being reported for the first time.

Flavonoids and hydroxycinnamates are the widespread biophenolic secondary plant metabolites that have received considerable interest on account of their possible antioxidative role in the prevention of various degenerative disorders and protective effects in diseases associated with oxidative stress ${ }^{6}$. Results emerging from epidemiological studies involving short-term human interventions, experimental animal investigations and in vitro probes tend to suggest that high dietary intake of biophenols

Table 1: Reactive species scavenging and Fe" chelating capacities of various fractions of $\boldsymbol{A}$. bettzickiana leaf extract

\begin{tabular}{llcc}
\hline \multirow{2}{*}{$\begin{array}{l}\text { Fractions } \\
\text { analysed }\end{array}$} & \multicolumn{2}{c}{ Relative Percentage $^{\mathrm{a}}$} \\
\cline { 2 - 3 } & \multicolumn{2}{c}{ VCEAC } & $\begin{array}{c}\text { Fe"l } \\
\text { Chelation }\end{array}$ \\
\cline { 2 - 3 } & ABTS & FRAP & $17.4 \pm 1.8$ \\
\hline $\mathrm{F}_{1}$ & $08.2 \pm 0.4$ & $06.9 \pm 0.2$ & $81.5 \pm 2.1$ \\
$\mathrm{~F}_{2}$ & $59.1 \pm 1.2$ & $50.9 \pm 1.4$ & $73.1 \pm 1.7$ \\
$\mathrm{~F}_{3}$ & $67.2 \pm 0.9$ & $63.8 \pm 1.4$ & $77.1 \pm 2.2$ \\
$\mathrm{~F}_{4}$ & $65.9 \pm 1.2$ & $58.1 \pm 3.0$ & $92.9 \pm 1.6$ \\
Rutin & $84.1 \pm 2.4$ & $80.6 \pm 3.1$ & \\
\hline
\end{tabular}

${ }^{\text {aMean }} \pm$ standard deviation $(\mathrm{n}=3)$

is strongly linked with potential health benefits. Among the scores of health implications highlighted for the biophenols, cardiovascular health, ability to exert beneficial cognitive effects and to reverse specific agerelated neurodegeneration, capacity to exert a variety of anti-carcinogenic effects (including an ability to induce apoptosis in tumour cells, inhibit cancer cell proliferation and prevent angiogenesis and tumour cells invasion) appear to be more promising ${ }^{6}$. They might also exert several other specific biological effects, including inhibition of cholesterol uptake, modulation of different enzymes including telomerase, cyclooxygenase and lipoxygenase and might also interact with several signal transduction pathways. They have also been found to affect caspasedependent pathways, cell cycle regulation and platelet functions and are capable of preventing endothelial dysfunctions ${ }^{6}$.

\section{Determination of in vitro antioxidant and metal ion chelating capacities}

The antioxidant capacity of the more polar hydrophilic fraction of the extract has been evaluated by measuring the capacities of 
the extract-fractions (i) to scavenge stable ABTS •+ radicals, (ii) to reduce $\mathrm{Fe}^{\text {III }}$ to $\mathrm{Fe}^{\text {II }}$ and (iii) to inhibit Fe"-ferrozine complex formation (Table 1). The VCEAC, determined by the two standard protocols were in the order, Rutin $>F_{3}>F_{4}>F_{2}>F_{1}$ and the ferrous ion chelating capacities varied in the order, Rutin $>\mathrm{F}_{2}>\mathrm{F}_{4}>\mathrm{F}_{3}>\mathrm{F}_{1}$.

Like any sister vegetable plant family distributed around the globe ${ }^{17,18}$, viz., Alliaceae (syn. Liliaceae, Amaryillidaceae; Onion family), Apiaceae (syn. Umbelliferae; Carrot/Parsley family), Asteraceae (syn. Compositae; Sunflower/Aster family), Brassicaceae (Cruciferae; Cabbage/Mustard family), Chenopodiaceae (Goosefoot family), Cucurbitaceae (Pumpkin/Gourd family), Lamiaceae (syn. Labiatae; Mint family), Leguminosae (syn. Fabaceae; Pea/Pulse/Bean family), Malvaceae (Hibiscus/Mallow family, Poaceae (syn. Graminae; Grasses/Grains), Solanaceae (Potato/Nightshade/ Tobacco family), the Amaranthaceae (Amaranth/ Pigweed family) is also reported to be rich in antioxidant components. Studies have correlated the antioxidant activity of amaranthus leaf extracts to the phenolic content of both the fresh and the blanched green leafy vegetables ${ }^{19-22}$. An investigation on human subjects has demonstrated that apigenin gets absorbed systemically by subjects fed with a diet high in parsley, resulting in the elevated levels of the antioxidant enzymes, erythrocyte glutathione reductase and superoxide dismutase ${ }^{23}$, with no alterations in their activities. Other biological effects induced by the metabolite include the reduction of plasma levels of low-density lipoproteins, inhibition of platelet aggregation, and reduction of cell proliferation ${ }^{24-27}$. This fact is apparent from another cross-sectional study conducted in Japan in which the total intake of flavonoids among women was found to be inversely correlated with plasma total cholesterol and low-density lipoprotein concentration $^{28}$. The effects of flavonoids on the hematologic systems have also been investigated by a 7-day study trial among 18 healthy men and women, examining the effects of a daily dietary supplement containing quercetin and apigenin on platelet aggregation and other hemostatic variables. It has been observed that no significant changes in collagen- or ADP- induced platelet number, factor VII, plasminogen, and PAI-1 activity or fibrinogen concentrations ${ }^{29}$. Ample studies from the laboratory front too have established that apigenin and related compounds promote metal chelation, scavenge<smiles>[R]Oc1c([R2])c(O)c2c(=O)cc(-c3ccc(O)cc3)oc2c1[R]</smiles><smiles>CC(O)C(O)C(O)C(O)CCO</smiles>

$\mathrm{R}^{1}=\mathrm{H}, \mathrm{R}^{2}=\mathrm{R}^{3}=\beta$-D-glucopyranosyl; 7-O- $\beta$-D-glucopyranosyl-6-C- $\beta$-D-glucopyranosylapigenin (1)

$\mathrm{R}^{1}=\mathrm{R}^{3}=\mathrm{H}, \mathrm{R}^{2}=\beta$-D-glucopyranosyl; 6-C- $\beta$-D-glucopyranosylapigenin (2)

$\mathrm{R}^{1}=\beta$-D-glucopyranosyl; $\mathrm{R}^{2}=\mathrm{R}^{3}=\mathrm{H}$; 8-C- $\beta$-D-glucopyranosylapigenin (3)

$R^{1}=R^{2}=R^{3}=H ; 5,7,4^{\prime}$-trihydroxyflavone (apigenin) (4)<smiles>[R4]c1cc(/C=C/C(=O)O)ccc1O</smiles>

$\mathrm{R}^{4}=\mathrm{H}$; (E)-3-(4-hydroxyphenyl)prop-2-enoic acid (5)

$\mathrm{R}^{4}=\mathrm{OH}$; (E)-3-(3,4-dihydroxyphenyl)prop-2-enoic acid (6)

$\mathrm{R}^{4}=\mathrm{OCH}_{3}$; (E)-3-(4-hydroxy-3-methoxyphenyl)prop-2-enoic acid (7) 
free radicals, and stimulate phase II detoxification enzymes in cell culture and in in vivo tumor models ${ }^{30}$. Exposure to apigenin prior to a carcinogenic insult has been reported to afford a protective effect in murine skin and colon cancer models ${ }^{31,32}$. Apigenin is claimed to be a strong inhibitor of ornithine decarboxylase, an enzyme that plays a major role in tumor promotion ${ }^{33}$. In addition, apigenin has been shown to increase the intracellular concentration of glutathione, enhancing the endogenous defense against oxidative stress ${ }^{34}$.

The anti-inflammatory property of apigenin is evident from studies that have shown the suppression of LPS-induced cyclooxygenase-2 and nitric oxide synthase-2 activity and expression in mouse macrophages ${ }^{35}$. They also act as strong inhibitors of IL-4 production ${ }^{36}$, which has been further confirmed in ovalbumin-immunized BALB/C mice, where production of IL-4 was down-regulated by apigenin ${ }^{37}$. Studies have also demonstrated the effects of apigenin on the immune system in C57BL/6 mice ${ }^{37}$. Other important targets of apigenin include heat shock proteins ${ }^{38}$, telomerase ${ }^{39}$, fatty acid synthase ${ }^{40}$, matrix metalloproteinases ${ }^{41}$, and aryl hydrocarbon receptor activity ${ }^{42} \mathrm{HER} 2 /$ neu $^{43}$, casein kinase $2 \alpha^{44}$, all of which have due relevance to the development of various human diseases.

Hydroxycinnamates, including compounds
5-7 and their derivatives are equally ubiquitous and render potent antioxidant activity by scavenging hydroxyl radical, superoxide radical anion, several other organic radicals, peroxyl radical, peroxinitrite and singlet oxygen, among others, with similar implications in human health ${ }^{45-46}$.

\section{CONCLUSION}

The principal dietary sources of biophenols are fruits and beverages, leguminous plants, leafy greens and other vegetables. The much coveted health implications of biophenols are being ascribed largely to their potent antioxidant capacity. Emerging findings are also suggestive of a much more significantly potential mechanisms of action of biophenols in preventing disease, which may be independent of their conventional antioxidant activities. These characteristics have also made food plant phenolics as potentially interesting materials for the development of functional foods and possibly as chemopreventives of therapeutic significance for the prevention of certain degenerative diseases, particularly those related to aging. To establish evidence for the effects of polyphenol consumption on human health and to better identify which polyphenols provide the greatest effectiveness in disease prevention, it is essential to determine the nature and the distribution of these compounds in our diet.

\section{REFERENCES}

1. Quattrocchi, U. CRC World Dictionary of Medicinal and Poisonous Plants, CRC Press, Taylor \& Francis Group, Boca Raton, 2012, 214-215.

2. Petrus, A.J.A.; Kalpana, K.; Bharadha Devi, A. Oriental J. Chem. 2014, 30(2), 491-499.

3. Chen, C.-H.; Chan, H.-C.; Chu, Y.-T.; Ho, H.-Y.; Chen, P.-Y.; Lee, T.-H.; Lee, C.-K. Molecules 2009, 14(8), 2947-2958.

4. Phusrisom, S.; Chatuphonprasert, W.; Monthakantirat, O.; Pearaksa, P.; Jarukamjorn K. J. Applied Biopharmaceutics Pharmacokinetics, 2013, 1(2), 64-71.

5. Cai,Y.; Sun, M; Corke, H. J. Agric. Food Chem. 2001, 49(4), 1971-1978.
6. Petrus, A.J.A. Asian J Chem. 2014, 26(16), 4929-4939.

7. Petrus, A.J.A.; Seetharaman, T.R. Indian J. Pharm. Sci. 2005, 67(2), 187-193.

8. Petrus, A.J.A.; Bhuvaneshwari, N.; Alain, J.A.L. Indian J. Nat. Prod. Resour., 2011, 2(1), 34-43.

9. Markham, K.R. Techniques of flavonoid identification, Academic Press, London 1982.

10. Petrus, A.J.A.; Bhuvaneshwari, N. Asian J. Chem. 2012, 24(3), 1261-1267.

11. Petrus, A.J.A. Asian J Chem. 2011, 23(7), 3014-3020.

12. Sivakumar, R.; Nair, A.G.R., Fitoterapia 
1992, 63(2), 189.

13. Narayanan, M.K.R.; Anil Kumar, N.; Balakrishnan, V.; Sivadasan, M.; Alfarhan, H.A; Alatar, A.A. J. Med. Plants Res., 2011, 5(15), 3520-3529.

14. Narayanan, M.K.R.; Anil Kumar, N. Indian J. Trad. Knowledge, 2007, 6(1), 204-216.

15. Meghashri, S; Vijay Kumar, H.; Gopal, S. Food Chem., 2010, 122(1), 105-110.

16. Anbazhagi, T.; Kadavul, K.; Suguna, G.; Petrus, A.J.A. Nat. Prod. Rad., 2009, 8(2), 151-157.

17. Fake, C. Vegetable plant families and their characteristics. http://ucanr.edu/sites/ placernevadasmallfarms/files/170644.pdf

18. Petrus, A.J.A. Asian J. Chem. 2012, 24(6), 2361-2368.

19. Amin, I., Norazaidah, Y.; Emmy Hainida, K.I. Food Chem. 2006, 94(1), 47-52.

20. Oboh, G. LWT-Food Sci. Technol. 2005, 38(5), 513-517.

21. Pacifico, S.; D’Abrosca, B.; Golino, A.; Mastellone, C.; Piccolella, S.; Fiorentino, A.; et al. Food Sci. Tech. 2008, 41(9), 1665-1671.

22. Saxena, R.; Venkaiah, K.; Anitha, P.; Venu, L.; Raghunath, M. Int. J. Food Sci. Nutr. 2007. 58(4), 250-260.

23. Nielsen, S.E.; Young, J.F.; Daneshvar, B.; Lauridsen, S.T.; Knuthsen, P.; Sandstrom, B.; Dragsted, L.O. Br. J. Nutr. 1999, 81(6), 447-455.

24. O’Prey, J.; Brown, J.; Fleming, J.; Harrison, P.R. Biochem. Pharmacol. 2003, 66(11), 2075-2088.

25. Surh, Y.J. Nat. Rev. Cancer, 2003 3(10), 768780.

26. Thiery-Vuillemin, A.; Nguyen, T.; Pivot, X.; Spano, J. P.; Dufresnne, A.; Soria, J. C. Eur. J. Cancer 2005, 41(13), 2003-2015.

27. Lambert, J.D.; Hong, J.; Yang, G.-y.; Liao, J.; Yang, C.S. Am. J. Clin. Nutr. 2005, 81(suppl), 284S-291S.

28. Arai, Y.; Watanabe, S.; Kimira, M.; Shimoi, K.; Mochizuki, R.; Kinae, N. J. Nutr. 2000, 130(9), 2243-2250.

29. Janssen, K.; Mensink, R.P.; Cox, F.J.; Harryvan, J.L.; Hovenier, R.; Hollman, P.C.; Katan, M.B. Am. J. Clin. Nutr. 1998, 67(2), 255-262.
30. Middleton, Jr. E.; Kandaswami, C.; Theoharides, T.C. Pharmacol. Rev. 2000, 52(4), 673-751.

31. Birt, D.F.; Mitchell, D.; Gold, B.; Pour, P.; Pinch, H. C. Anticancer Res. 1997, 17(1A), 85-91.

32. Van Dross, R.; Xue, Y.; Knudson, A.; Pelling, J. C. J. Nutr. 2003, 133(11Suppl 1), 3800S-3840S.

33. Wei, H.; Tye, L.; Bresnick, E.; Birt, D. F. Cancer Res. 1990, 50(3), 499-502.

34. Myhrstad, M.C.; Carlsen, H.; Nordstrom, O.; Blomhoff, R.; Moskaug, J.O. Free Radic. Biol. Med. 2002, 32(5), 386-393.

35. Liang, Y.C.; Huang, Y.T.; Tsai, S.H.; Lin-Shiau, S.Y.; Chen, C.F.; Lin, J.K. Carcinogenesis 1999, 20(10), 1945-1952.

36. Kawai, M.; Hirano, T.; Higa, S.; Arimitsu, J.; Maruta, M.; Kuwahara, Y.; Ohkawara T, Hagihara K, Yamadori T, Shima Y, Ogata A, Kawase I, Tanaka T.. Allergol. Int. 2007, 56(2), 113-123.

37. Yano, S.; Umeda, D.; Yamashita, T.; Ninomiya, Y.; Sumida, M.; Fujimura, Y.; Yamada, K.; Tachibana, H. Eur. J. Nutr. 2007, 46(5), 257 263.

38. Osada, M.; Imaoka, S.; Funae, Y. FEBS Lett. 2004, 575(1-3), 59-63.

39. Menichincheri, M.; Ballinari, D.; Bargiotti, A.; Bonomini, L.; Ceccarelli, W.; D'Alessio, R.; Fretta A.; Moll. J.; Polucci, M.; Soncini, C.; Tibolla, M.; Trosset, J-Y.; Vanotti, E. J. Med Chem. 2004, 47, 6466-6475.

40. Brusselmans, K.; Vrolix, R.; Verhoeven, G.; Swinnen, J.V. J. Biol. Chem. 2005, 280(7), 5636-5645.

41. Kim, M.H.J. J. Cell Biochem. 2003, 89(3), 529-538.

42. Reiners, Jr. J.J.; Clift, R.; Mathieu, P. Carcinogenesis 1999, 20(8), 1561-1566.

43. Way, T.D.; Kao, M.C.; Lin, J.K. J. Biol. Chem. 2004, 279(6), 4479-4489.

44. Kim, J.S.; Eom, J.I.; Cheong, J.W.; Choi, A.J.; Lee, J.K.; Yang, W.I.; Min YH. Clin. Cancer Res. 2007, 13(3), 1019-1028.

45. Shahidi, F.; Chandrasekara, A. Phytochem. Rev. 2010, 9(1), 147-170.

46. Magnani, C.; Isaac, V.L.B.; Correa, M.A.; Salgado, H.R.N. Anal. Methods, 2014, 6(10), 3203-3210. 